\title{
NEUTROPHILS-TO-LYMPHOCYTE AND PLATELET-TO-LYMPHOCYTE RATIO AND SYSTEMIC LUPUS ERYTHEMATOSUS ACTIVITY: A CROSS-SECTIONAL STUDY IN BRAZILIAN PATIENTS
}

Jady Elen de Pontes ${ }^{1, \star}$, Thiago Alberto Fernandes Gomes dos Santos ${ }^{1}$, Thelma Larocca Skare ${ }^{1}$

1.Hospital Universitário Evangélico Mackenzie, Curitiba (PR), Brazil.

${ }^{\star}$ Corresponding author: drajadypontes@gmail.com

\section{BACKGROUND}

To identify disease activity in systemic lupus erythematosus (SLE) is important to choose the correct treatment. Neutrophil/ lymphocyte $(\mathrm{N} / \mathrm{L})$ and platelet/lymphocytic $(\mathrm{P} / \mathrm{L})$ ratio have been considered to reflect inflammatory status in several situations. The aim is to evaluate the association of $N / L$ and $P / L$ with SLE disease activity.

\section{METHODS}

Cross-sectional study of 189 SLE patients for disease activity for SLEDAI-2K, erythrocyte sedimentation rate (ESR), C-reactive protein (CRP) and hemogram with $\mathrm{N} / \mathrm{L}$ and $\mathrm{P} / \mathrm{L}$ ratio.

\section{RESULTS}

The $\mathrm{N} / \mathrm{L}$ ratio demonstrated correlation with SLEDAI (rho $=0.24 ; p=0.0009)$ ESR (rho $=0.17 ; p=0.02)$ and CRP (rho $=0.23$; $p=0.004) ; P / L$ correlated with SLEDAI (rho $=0.21 ; p=0.003), \operatorname{CRP}($ rho $=0.26 ; p=0.001)$, ESR ( $r$ ho $=0.23 ; p=0.003$ ) and levels of anti-dsDNA (rho $=0.29 ; p=0.02$ ) and had a negative correlation with hemoglobin ( $r h o=-0.27 ; p=0.0001$ ). A cut-off of 2.28 in $\mathrm{N} / \mathrm{L}$ ratio had sensitivity of $68.6 \%$ and specificity of $68.2 \%$ for active disease; a cutoff of 124.1 in $P / L$ ratio had sensitivity of 82.9 and specificity of $41.1 \%$ for active SLE.

\section{CONCLUSION}

The $N / L$ and $P / L$ ratios are useful in the evaluation of SLE disease activity.

\section{KEYWORDS}

Systemic lupus erythematosus, Evidence of inflammatory activity, Disease activity. 